\title{
The role of $\mathrm{CB}_{1}$ in intestinal permeability \& inflammation
}

Mustafa A. Karwad ${ }^{1}$, Daniel G Couch ${ }^{1}$, Elena Theophilidou ${ }^{1}$, Sarir Sarmad ${ }^{3}$, David A. Barrett ${ }^{3}$, Michael Larvin ${ }^{4}$, Karen L. Wright ${ }^{2}$, Jonathan N. Lund ${ }^{1}$ and Saoirse E. O’Sullivan ${ }^{1 *}$

${ }^{1}$ School of Medicine, Royal Derby Hospital, University of Nottingham, UK

${ }^{2}$ Division of Biomedical and Life Sciences, Faculty of Health and Medicine, Lancaster University, UK

${ }^{3}$ Centre for Analytical Bioscience, School of Pharmacy, University of Nottingham, Nottingham, NG7 2RD, UK

${ }^{4}$ Graduate Entry Medical School, University of Limerick, Limerick, Ireland

*Correspondence

Daniel Couch, School of Medicine, Royal Derby Hospital, University of Nottingham, Derby. DE22 3DT UK

$\underline{\text { Tel:013320824669 }}$

\section{Running Title:}

Endocannabinoids control permeability and inflammation via $\mathrm{CB}_{1}$ 


\section{List of Abbreviations}

AEA

2-AG

NAPE

NAPE PLD

NAAA

FAAH

MAGL

DAGL

LPS

TEER
Anandamide

2-Arachidonoyl glycerol

$\mathrm{N}$-acylphosphatidylethanolamine

$\mathrm{N}$-acylphosphatidylethanolamine phospholipase D

$\mathrm{N}$-acyl ethanolamine-hydrolysing acid amidase

Fatty acid amide hydrolase

Monoacylglycerol lipase

Diacylglycerol lipase

Lipopolysaccharide

Transepithelial electrical resistance 
BACKGROUND:The endocannabinoid system has previously been shown to play a role in the permeability and inflammatory response of the human gut. Our study was to determine the effects of endogenous AEA and 2-AG on the permeability and inflammatory response of intestinal epithelium under normal, inflammatory and hypoxic conditions.

METHODS:Human intestinal mucosa was modelled using Caco-2 cells. Human tissue was collected from planned colorectal resections. Accumulation of AEA and 2-AG was achieved by inhibiting their metabolising enzymes URB597 (FAAH inhibitor) and JZL184 (MAGL inhibitor). Inflammation and ischaemia were simulated with TNF $\alpha$ and IFN $\gamma$ and oxygen deprivation. Permeability changes were measured by transepithelial electrical resistance (TEER). The role of the $\mathrm{CB}_{1}$ receptor was explored using $\mathrm{CB}_{1}$ knock down $\left(\mathrm{CB}_{1} \mathrm{Kd}\right)$ intestinal epithelial cells. Endocannabinoid levels were measured using LC-MS. Cytokine secretion was measured using multiplex and ELISA.

RESULTS: URB597 and JZL184 caused a concentration-dependent increase in permeability via $\mathrm{CB}_{1}(\mathrm{p}<0.0001)$, and decreased cytokine production. Basolateral application of JZL184 decreased permeability via $\mathrm{CB}_{1}(\mathrm{p}<0.0001)$. URB597 and JZL184 increased the enhanced (worsened) permeability caused by inflammation and hypoxia ( $\mathrm{p}<0.0001$ and $<0.05)$. $\mathrm{CB}_{1} \mathrm{Kd}$ cells showed reduced permeability response to inflammation $(\mathrm{p}<0.01)$ but not hypoxia. 2-AG levels were increased in response to inflammation and hypoxia in Caco-2 cells. In human mucosal tissue, inflammation increased the secretion of GM-CSF, IL-12, IL-13 and IL-15, which was prevented with ex vivo treatment with URB597 and JZL184, and inhibited by a CB $_{1}$ antagonist.

CONCLUSION: Endogenous AEA and 2-AG production and $\mathrm{CB}_{1}$ activation play a key modulatory roles in normal intestinal mucosa permeability, and also in inflammatory and hypoxic conditions.

Keywords: Gut, Endocannabinoids, Anandamide, 2-AG, Inflammation 


\section{Introduction}

A key function of the gastrointestinal tract is to form a barrier between the noxious exterior environment and sterile submucosa, whilst actively absorbing the vital nutrients necessary for homeostasis (1). This selective permeability is achieved through a set of complex mechanisms including the secretion of a mucous barrier at the epithelial layer, production of mucosal antibodies by immune cells and through a continuous layer of epithelial cells bound together by specialised tight junctions (2-5). Dysregulation of these mechanisms has been shown to lead to intestinal diseases such as Crohn's disease, Ulcerative Colitis, Coeliac disease, and Irritable Bowel Syndrome (6-9). Despite increasing interest in the factors governing permeability and inflammation within the gut, the responsible mechanisms have not yet been fully elucidated.

Endocannabinoids are intercellular lipid signalling molecules derived on demand from membrane precursors, themselves derived from arachidonic acid (10). The two most well described ligands within this system are anandamide (AEA) and 2-arachidonoyl glycerol (2-AG). AEA production commences with the activation of $\mathrm{N}$-acyltransferase, promoting the conversion of the membrane lipid phosphatidylethanolamine to $\mathrm{N}$-acylphosphatidylethanolamine (NAPE). This in turn is converted by NAPE phospholipase D (NAPE-PLD) into AEA (11). AEA is transported across into the intracellular compartment and catabolised by fatty acid amide hydrolase (FAAH) and N-acyl ethanolamine-hydrolysing acid amidase (NAAA) $(11,12)$. 2-AG is produced by the hydrolysis of phosphatidylinositol to diacylglycerol (13). This is converted to 2-AG by the action of diacylglycerol lipase (DAGL). Following its biological effects, 2-AG is transported to the intracellular compartment and catabolised to arachidonic acid by monoacylglycerol lipase (MAGL), though may also be catabolised by FAAH, serine hydrolase $\alpha$ - $\beta$-hydrolase domain 6 (ABHD6) and serine hydrolase $\alpha$ - $\beta$-hydrolase domain (ABHD12) $(12,14)$. Both AEA and 2-AG are agonists of the two major cannabinoid $\mathrm{G}$-coupled protein receptors $\mathrm{CB}_{1}$ and $\mathrm{CB}_{2}$, but also at other non-classical sites including TRPs, PPARs, and GPR55.

AEA and 2-AG have been shown to play roles in gut motility, nausea, and nociception (15). We have also shown that AEA and 2-AG, acting at $\mathrm{CB}_{1}$, increase intestinal permeability in healthy Caco-2 cells, and worsen the increased permeability caused by hypoxia and cytokine-induced inflammation $(16,17)$. These findings, taken with evidence showing that patients with active colitis have increased colonic levels of AEA and 2-AG, and that endocannabinoid production is increased 
during sepsis, suggested that AEA or 2-AG acting at the $\mathrm{CB}_{1}$ receptor increase permeability and may act to decrease inflammation $(18,19)$. Blockade of the $\mathrm{CB}_{1}$ receptor has been shown to limit the hypotensive and vasodilator effects of lipopolysaccharide (LPS) in rats, and to protect the rat liver from endotoxaemia and prolonged the survival of rats with severe acute pancreatitis (20-22). However, several studies have also shown that AEA protects against gastrointestinal disease (2326). Engel et al. found that intraperitoneal administration of AEA to mice with trinitro benzosulphonic acid (TNBS) induced colitis reduced macro- and microscopic colitis scores, reduced pro-inflammatory cytokine production and also reduced immune cell infiltration, suggesting decreased gut permeability (23). More recently two similar studies showed that inhibition of FAAH, causing accumulation of AEA, will decrease production of pro-inflammatory cytokines and reduce proliferation of leucocytes and lead to decreased colitis scores in experimental murine colitis induced by dextran sodium sulphate (DSS) $(27,28)$. However data regarding the effects of AEA and 2-AG in human tissue are lacking. We hypothesised that endogenously produced $\mathrm{AEA}$ and 2-AG may act to increase permeability via $\mathrm{CB}_{1}$ as per our previous findings $(16,17)$, whilst having a separate but simultaneous anti-inflammatory effect.

To address the hypothesis, the aim of the present study was to determine the effects of endogenously produced AEA and 2-AG on the permeability and inflammatory response of intestinal epithelial cells under normal, inflammatory and hypoxic conditions. To achieve this we caused accumulation of AEA and 2-AG by inhibition of their metabolising enzymes with URB597 (a FAAH inhibitor) and JZL184 (a MAGL inhibitor). The role of the $\mathrm{CB}_{1}$ receptor was explored using $\mathrm{CB}_{1}$ knock down $\left(\mathrm{CB}_{1} \mathrm{Kd}\right)$ intestinal epithelial cells and $\mathrm{CB}_{1}$ and TRPV1 antagonists in explant human colonic tissue. 


\section{Materials and Methods}

Caco-2 cells (European Collection of Cell Culture, Wiltshire, UK; passages 62-86) were cultured in T75 cell culture flasks in Minimal Essential Medium Eagle supplemented with $10 \%$ fetal bovine serum (FBS), $1 \%$ penicillin/streptomycin and L-glutamine at $37^{\circ} \mathrm{C}$ in $5 \% \mathrm{CO}_{2}$ and $95 \%$ air. In some experiments, the $\mathrm{CB}_{1}$ receptor was knocked down as previously described (29). For this, wild type Caco-2 cells were seeded at $2 \times 10^{5}$ cells per well in a 6-well culture plate overnight before transfection with 29-mer shRNA corresponding specifically to the human Cnr1 receptor gene in retroviral HuSH pRS plasmid vector (Gene ID = 1268; OriGene product code: TR316500; Insight Biotechnology Limited, Middlesex, UK) for $48 \mathrm{~h}$, termed $\mathrm{CB}_{1} \mathrm{Kd}-\mathrm{Caco}-2$. Vector control cells (termed control-Caco2) were transfected with non-effective 29-mer scrambled shRNA cassette in the pRS plasmid vector. All procedures were performed based on the manufacturer's protocol using TurboFectin 8.0 transfection reagent (OriGene product code: TF81001; Insight Biotechnology Limited, Middlesex, UK). After 48h, cells were transferred to 96-well plates and maintained in complete medium with puromycin $(0.06 \mu \mathrm{L} / \mathrm{mL})$ for selection. Within two weeks, 3 to 4 clonal populations of cells were selected, passaged and cultured for experiments with continued selection pressure. Transfection efficiency was checked by immunoblotting for $\mathrm{CB}_{1}$ receptor expression (see method below) using $\left(\mathrm{CB}_{1}\right.$ receptor antibody (1:1000; Cambridge Bioscience \# 10006590) (Koay et al, 2014). Two clones were further assessed for $\mathrm{CB}_{1}$ receptor knockdown by the [35S] GTP $\gamma \mathrm{S}$ binding assay using the synthetic $\mathrm{CB}_{1}$ receptor agonist, arachidonyl-2'-chloroethylamide (ACEA) as per Shore et al. 2014 (30). One clone was taken forward for further experiments.

For permeability studies, cells were seeded at 20,000 cells on $6.4 \mathrm{~mm}$ diameter, $0.4 \mu \mathrm{m}$ pore size polyethylene terephthalate inserts (BD Biosciences, Bedford, UK) and grown for 14-18 days. Transepithelial electrical resistance (TEER) was measured using a voltohmmeter $\left(\mathrm{EVOM}^{2}\right)$ (World Precision Instruments, Sarasota FL, USA) as an indicator of cellular permeability. Caco-2 cell monolayers with TEER value greater than $1000 \Omega . \mathrm{cm}^{2}$ were used. Caco-2 cell monolayers were washed twice in HBSS (+ N-2-hydroxyethylpintestinal permeabilityerazine-N'-2-ethanesulfonic acid or HEPES and P/S) and baseline TEER measured.

To establish the effect of endocannabinoid degradation inhibition on Caco-2 permeability, URB597 (FAAH inhibitor, IC 50 low nM), JZL184 (MAGL inhibitor, IC 50 low nM) (1nM-10 $\mu$ M) or DMSO (vehicle $0.01 \%$ ) were applied to the Caco-2 monolayer apical or basolateral membranes. TEER 
measured every 30 minutes for the first 2 hours and at 8, 24, 36 and 48 hours. To identify the target sites of action, the receptor antagonists AM251 (100nM), AM630 (100nM), GW9662 (100nM), GW6471 (500nM), capsazepine (500nM), SB 366791 (100nM) and O-1918 (500nM) were coapplied with URB597 or JZL184. The effects of $10 \mu$ M URB597 and JZL184 were also tested in $\mathrm{CB}_{1} \mathrm{Kd}$ Caco-2 cells.

To investigate the effects of AEA and 2-AG basolaterally on Caco-2 cell permeability, cell monolayers were washed twice in HBSS and baseline TEER in each insert was measured. Endocannabinoids AEA and 2-AG $(10 \mu \mathrm{M})$ or vehicle $(0.1 \%$ ethanol) were applied to the basolateral compartment of inserts and TEER was measured every 30 minutes for 2 hours and after 8, 24, 36 and 48 hours.

\section{Inflammatory model}

Caco- 2 cell monolayers were grown on transwell inserts. $10 \mathrm{ng} \cdot \mathrm{ml}^{-1}$ interferon-gamma (IFN $\gamma$ ) was added to the basolateral compartment and after 8 hours, $10 \mathrm{ng} \cdot \mathrm{ml}^{-1}$ of tumour necrosis factor-alpha (TNF $\alpha$ ) was added to the media for another 16 hours as previously described (17). URB597, JZL184 or vehicle (DMSO $0.01 \%$ ) were applied to either the apical or basolateral membranes as indicated. In some experiments, this protocol was carried out in the $\mathrm{CB}_{1} \mathrm{Kd}$ cells.

\section{Ischaemia/reperfusion model}

Caco-2 cell monolayers were grown on transwell inserts. Hypoxic conditions were simulated using a GasPak ${ }^{\mathrm{TM}}$ EZ Anaerobe Pouch System (BD Biosciences, Bedford, UK) for 4 hours after which

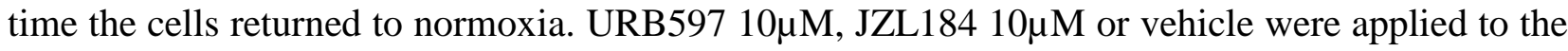
Caco-2 membranes. In some experiments, this protocol was carried out in the $\mathrm{CB}_{1} \mathrm{Kd}$ cells and for more prolonged periods of hypoxia (6 and $8 \mathrm{~h})$.

\section{Measurement of cytokine production}

To quantify the effect of AEA, 2-AG, URB597 and JZL184 on the inflammatory response in caco2 cells we measured the media concentrations of two key cytokines involved in the cell stress response, interleukin 8 (IL-8) and IL-6, after 24 hours of incubation. Concentrations were measured 
using ELISA according to manufacturer's instructions (IL-8 and IL-6, both DUOSET ELISA kits R\&D Systems Minneapolis, US).

\section{Measurement of endocannabinoid levels}

A quantitative LC-MS/MS method was used for analysis of AEA and 2-AG levels in cell samples, based on a previously reported procedure (31). For these experiments, Caco-2 cells were grown in T75 flasks and subjected to the inflammatory or ischaemia/reperfusion protocols. Cell lysates and medium were stored at $-80^{\circ} \mathrm{C}$ before analysis. Internal standard $(0.42 \mathrm{nmol}$ AEA-d8) was added to a $0.4 \mathrm{ml}$ aliquot of each sample followed by solvent extraction (ethyl acetate: hexane; 9:1 v/v), centrifugation and evaporation. Prior to analysis, each sample extract was reconstituted in acetonitrile. An Applied Biosystems MDS SCIEX 4000 Q-Trap hybrid triple-quadrupole-linear ion trap mass spectrometer (Applied Biosystems, Foster City, CA, USA) operated in positive electrospray ionisation mode was used in conjunction with a Shimadzu series 10AD VP LC system (Shimadzu, Columbia, MD, USA) using an ACE 3 C8, 100 x $2.1 \mathrm{~mm}, 3 \mu \mathrm{m}$ particle size column (Advanced Chromatography Technologies Ltd., Aberdeen, UK). Quantification was performed by measuring specific AEA and 2-AG precursor and product ions together with a calibrated internal standard method.

\section{Human Tissue Experimentation}

Experiments on ex vivo human colonic tissue were performed by obtaining healthy colonic tissue from patients undergoing elective bowel resection for bowel cancer at Royal Derby Teaching Hospital NHS Trust, Derbyshire $(n=7)$. After gaining informed consent, samples of normal colon at least $10 \mathrm{~cm}$ proximal to any bowel tumour were obtained immediately after resection within the operating theatre. Sections of tissue $2 \mathrm{~cm} \times 2 \mathrm{~cm}$ were removed from the operative sample and transferred on ice to the laboratory within ten minutes, in pre-chilled Eagle's Minimum Essential Medium supplemented with $1 \%$ FBS $1 \%$ penicillin/streptomycin and $1 \%$ non-essential amino acids mixture (Sigma-Aldrich). Once in the laboratory, samples were pinned on Stylgard plates (Living Systems Instrumentation, VT, US) and the mucosa with submucosa was dissected free from the underlying muscularis layer. Mucosal samples were then further dissected into approximately 20 $2 \mathrm{~mm} \times 2 \mathrm{~mm}$ sections and placed in individual wells of 24-well polystyrene plates (Corning Incorporated, USA), each containing $1 \mathrm{ml}$ of media, treatments with inflammation as described 
above (IFN $\gamma$ and TNF $\alpha$ over 24 hours), in the absence or presence of URB597 and JZL184 or vehicle as appropriate in duplicate (DMSO $0.01 \%$ ), and in the presence of antagonists of $\mathrm{CB}_{1}$ (AM251) and TRPV1 (SB366791). Samples were incubated for 24 hours at $37^{\circ} \mathrm{C}$ in $5 \% \mathrm{CO} 2$ and 95\% humidity. At the end of the 24 hour experimental period media was collected and stored at $80{ }^{\circ} \mathrm{C}$ until analysis.

Levels of the cytokine Granulocyte Macrophage-Colony Stimulating Factor (GM-CSF), IL-12, IL13 and IL-15, IL-1 $\beta$, IL-10, MCP-1 and MIP1 $\alpha$ were measured from undiluted media using a Multiplex human cytokine assay according to the manufacturer's instructions (Merck Millipore Catalogue No. CYTOMAG-60K) using a Magpix plate reader (MAGPX 11326002, Luminex, Texas US).

\section{Chemicals}

AEA, 2-AG, AM251, AM630, GW9662, GW6471, SB366791 and capsazepine were purchased from Tocris Bioscience (Bristol, UK). JZL184 and URB597 were purchased from Sigma-Aldrich (Poole, UK). IFN $\gamma$ and TNF $\alpha$ were purchased from Invitrogen (Paisley, UK).

\section{Statistical analysis}

TEER values are stated as the mean $\_$standard error (SEM). Data recorded at each time point and for ELISA and mass spectrometry determinations of molecular concentrations were compared using one-way or two-way ANOVA as indicated. The overall effect over time of each drug was measured using area under the curve (AUC) values. Statistical significance between manipulations and controls were determined by Dunnett's post-hoc test. Significance was set at the 5\% level. Differences between experimental groups in human tissue experiments were compared using repeated measures-ANOVA, using post hoc Freidman testing where appropriate. All statistical analysis was performed using GraphPad Prism 7.01 (GraphPad Software Inc, La Jolla, USA). 


\section{Results}

\section{The effect of FAAH and MAGL inhibition on TEER}

To determine whether inhibiting the breakdown of AEA and 2-AG had an effect on TEER, URB597 and JZL184 were applied to the apical and basolateral compartments of Caco-2 monolayers. When applied to the apical membrane, URB597 (FAAH inhibitor) decreased Caco-2 monolayer resistance in a concentration-dependent manner, which was significantly different from vehicle at 1, 3 and 10 $\mu \mathrm{M}$ concentrations (Figure 1A). AUC analysis of the $48 \mathrm{hr}$ time course showed the effect of URB597 at the apical membrane was only inhibited by the $\mathrm{CB}_{1}$ receptor antagonist $\mathrm{AM} 251$ (Figure 1B). At the basolateral membrane, inhibition of FAAH activity with URB597 also caused a fall in TEER in a concentration-dependent fashion, significantly different from vehicle at 1,3 and $10 \mu \mathrm{M}$ concentration after 30 minutes of incubation and 300nM after $2 \mathrm{hr}$ of incubation (Figure 1C), and this effect was inhibited by $\mathrm{CB}_{1}$ antagonist AM251, and the TRPV1 receptor antagonist capsazepine (Figure 1D).

Apical application of the MAGL inhibitor JZL184 caused a decrease in TEER in a concentrationdependent manner, which was significantly different to vehicle at $300 \mathrm{nM}, 1 \mu \mathrm{M}, 3 \mu \mathrm{M}$ and $10 \mu \mathrm{M}$ concentrations (Figure 2A). This effect was only inhibited by the $\mathrm{CB}_{1}$ antagonist AM251 (Figure 2B). In contrast, application of JZL184 to the basolateral membrane increased TEER in a concentration-dependent manner after 2 hours (Figure 2C), again inhibited by AM251 (Figure 2D).

\section{Effects of basolateral application of AEA and 2-AG on TEER}

We have previously reported that apical application of AEA and 2-AG to Caco-2 monolayers decrease TEER but basolateral application was not examined previously (16). Based on the findings that basolateral application of JZL194 increased TEER, we examined the effects of basolateral application of AEA or 2-AG on TEER and found that 2-AG $(10 \mu \mathrm{M})$, but not AEA, increased TEER when applied to the basolateral membrane which was significantly different from vehicle after 2 hours (Figure 2E). 


\section{Effects of FAAH and MAGL inhibition on hyper-permeability induced by cytokines or hypoxia}

Since increasing cellular endocannabinoid levels with either URB597 or JZL184 increased Caco-2 permeability, we examined the effects of these compounds in times of increased permeability associated with inflammation or hypoxia. As expected, application of inflammatory cytokines to Caco-2 cells decreased TEER (Figure 3A). Application of URB597 $(10 \mu \mathrm{M})$ or JZL184 $(10 \mu \mathrm{M})$ at the apical membrane caused a further decrease in TEER beyond the effect of cytokines alone (Figure 3A). 4h hypoxia also caused a fall in TEER of Caco-2 monolayers with recovery occurring over $68 \mathrm{~h}$ (Figure 3B). Application of URB597 $(10 \mu \mathrm{M})$ or JZL184 $(10 \mu \mathrm{M})$ at the apical membrane prevented recovery of TEER over the experimental period compared to control. The recovery in TEER was reduced in the presence of both URB597 and JZL184 ( $<<0.05$ for both inhibitors at 72 hours).

\section{Effects of FAAH and MAGL inhibition on CB1Kd Caco-2 TEER}

To confirm the pharmacological data suggesting that the effects of FAAH and MAGL inhibition on permeability were $\mathrm{CB}_{1}$-mediated, we examined these compounds in $\mathrm{CB}_{1} \mathrm{Kd}$ Caco-2 cells. No effects of URB597 or JZL184 $(10 \mu \mathrm{M})$ were found when applied to the apical or basolateral membranes of $\mathrm{CB}_{1} \mathrm{Kd}$ Caco-2 cells (Figure $4 \mathrm{~A}$ ).

\section{Effects of cytokine and hypoxia on wild type and $\mathrm{CB} 1 \mathrm{kd}$ Caco-2 cells}

Because endogenous production of AEA and 2-AG appeared to govern paracellular permeability through $\mathrm{CB}_{1}$ (Figure $1 \mathrm{~B}, 2 \mathrm{~B}$ ), we sought to find the effect of reducing the $\mathrm{CB}_{1}$ receptor expression on Caco-2 permeability under inflammatory and hypoxic conditions. Basolateral application of cytokines to both $\mathrm{CB}_{1} \mathrm{Kd}$ and control cells caused a decrease in TEER (Figure 4B). However, the fall in TEER in $\mathrm{CB}_{1} \mathrm{Kd}$ cells was significantly less compared to control cells from $36 \mathrm{~h}$ to $72 \mathrm{~h}$ ( $p<0.05$ and 0.01 respectively, Figure 4B). By contrast, oxygen deprivation caused a similar fall in TEER in control and $\mathrm{CB}_{1} \mathrm{Kd}$ cells after $4 \mathrm{~h}$, $6 \mathrm{~h}$ or $8 \mathrm{~h}$ of hypoxia (Figure $4 \mathrm{C}$ ). In both $\mathrm{CB}_{1} \mathrm{Kd}$ and control cells, a recovery in TEER occurred after $4 \mathrm{~h}$ of hypoxia, though not after 6 or $8 \mathrm{~h}$ periods. 


\section{Effects of hypoxia and inflammation on the endogenous production of AEA and 2-AG}

Because inflammatory conditions and hypoxia caused a fall in TEER similar to the effect of FAAH and MAGL inhibition in non-inflamed Caco-2 cells, we sought to find the effect of hypoxia and inflammation on the endogenous production of AEA and 2-AG. Neither hypoxia nor inflammatory cytokines had any significant effect on the production of endogenous AEA (Figure 5A), however both conditions caused a significant increase in the production of $2-\mathrm{AG}(\mathrm{p}<0.0001$, Figure $5 \mathrm{~B})$.

\section{Effects of AEA and 2-AG on the production of inflammatory cytokines}

As inflammation, hypoxia, application of AEA or 2-AG, or inhibition of their degradation, caused a fall in TEER in Caco-2 monolayers, we sought to find if AEA or 2-AG have any proinflammatory effects after 24 hours of exposure. Externally applied AEA, URB597 and JZL184 caused a decrease in the production of IL-8 compared to vehicle (figure 5C), and AEA, 2-AG, URB597 and JZL184 all caused reduced levels of IL-6 (figure 5D), confirming their previously establish anti-inflammatory effects.

\section{Effect of URB597 and JZL184 on the production of inflammatory cytokines in human colonic tissue}

We then sought to find the effect of FAAH and MAGL inhibition on the inflammatory response in human colonic tissue, using Multiplex analysis to measure a range of cytokines. Inflammation caused a significant rise in the secretion of GM-CSF, IL13 and IL-15 (all p<0.05, fig 6 A, C \& D) and IL-12 ( $<<0.01$, fig 6 B), and a non-significant increase in the secretion of IL- $1 \beta$ and MIP-1 $\alpha$ (fig $6 \mathrm{E} \& \mathrm{~F}$ ). IFN $\gamma$ and TNF $\alpha$ did not affect the secretion of IL-10 and MCP-1 (data not shown). Both URB957 and JZL184 significantly prevented an increase in secretion of GM-CSF, IL-12, IL13 and IL-15 in the presence of inflammation. URB597 and JZL184 also prevented the nonsignificant increase in the secretion of IL-1 $\beta \alpha$ and MIP-1 $\alpha$. URB597 and JZL184 alone had no effect on any of the measured cytokine levels. The anti-inflammatory effects of URB597 and JZL184 were prevented by the AM251, but not SB366791 (fig 6). Alone, the $\mathrm{CB}_{1}$ and TRPV1 antagonists did not affect cytokine secretion. 


\section{Discussion}

We have previously shown that exogenously applied endocannabinoids increase the permeability of the intestinal epithelium $(16,17)$. In the present study, we sought to investigate the effects of the endogenously produced endocannabinoids AEA and 2-AG, by inhibiting their degradation, on intestinal permeability under control, inflammatory and hypoxic conditions, and explore the role of $\mathrm{CB}_{1}$ in modulating gut permeability. Our data show that FAAH and MAGL cause an increase in epithelial permeability through activation of $\mathrm{CB}_{1}$ at the apical surface in control conditions, or when permeability is increased by inflammation or hypoxia, whilst simultaneously reducing inflammatory cytokine levels in Caco-2 cells. Knockdown of the $\mathrm{CB}_{1}$ receptor reduced the permeability response to inflammation. In contrast, blocking endocannabinoid degradation under hypoxic conditions reduced the recovery of epithelial resistance. We also found that 2-AG is produced by intestinal epithelial cells in response to inflammation and hypoxia, but not AEA. Finally, we compared the anti-inflammatory effects of FAAH and MAGL inhibition seen in Caco2 cells to their effect on the inflammatory response in human tissue. We found that FAAH and MAGL inhibition in explant human colonic tissue were anti-inflammatory, and that $\mathrm{CB}_{1}$ blockade prevented their effects. We suggest that endogenous production of endocannabinoids by intestinal epithelial cells increases permeability and simultaneously prevents inflammation through $\mathrm{CB}_{1}$.

We previously reported that apical application of exogenous AEA and 2-AG increased permeability in Caco-2 monolayers and sought to examine in the present study whether upregulation of cellular endocannabinoids by inhibition of their degradation would have a similar effect. In agreement with our previous study we found that inhibition of FAAH and MAGL at the apical membrane causes increased permeability and this effect was inhibited by $\mathrm{CB}_{1}$ receptor antagonism or knockdown, confirming the role for $\mathrm{CB}_{1}$ in modulating gut permeability. As URB597 and JZL184 do not activate $\mathrm{CB}_{1}(32,33)$, this suggests that accumulation of endogenously produced AEA and 2-AG at the apical epithelial layer increase permeability via $\mathrm{CB}_{1}$ (16).

Treatment of Caco-2 cells with inflammatory cytokines caused nearly a $20 \%$ drop in TEER (increased permeability). Apical treatment with both URB597 or JZL184 caused a further decrease in TEER in addition to the effect of the cytokines, in line with our previous studies in which falls in TEER caused by inflammation were exacerbated by the apical application of AEA and 2-AG (17). Furthermore, hypoxia caused $\sim 35 \%$ drop in TEER, with recovery and return to baseline 
permeability over 72 hours. As in the inflammatory protocol, treatment with URB597 and JZL184 delayed the recovery of TEER compared to control cells. We therefore hypothesise that endocannabinoids, via $\mathrm{CB}_{1}$, play a key role in the development and recovery from permeability increases caused by inflammation. To investigate this hypothesis, we conducted similar permeability experiments with $\mathrm{CB}_{1} \mathrm{Kd}$ cells and found that $\mathrm{CB}_{1} \mathrm{Kd}$ monolayers exposed to inflammatory cytokines do not exhibit as great a decrease in permeability compared to control cells. However, no differences were seen between control and $\mathrm{CB}_{1} \mathrm{Kd}$ cells subjected to hypoxic conditions. This suggests that in the gut, $\mathrm{CB}_{1}$ is a critical component of the permeability changes seen in inflammation but not hypoxia.

Interestingly we have found that basolateral FAAH inhibition increased permeability and this was inhibited by antagonism of both $\mathrm{CB}_{1}$ and TRPV1. However, in the presence of $\mathrm{CB}_{1}$ knockdown, FAAH inhibition had no effect on permeability, i.e. no contribution of TRPV1 remained after $\mathrm{CB}_{1}$ knockdown. This suggests that at the basolateral layer the ability for TRPV1 to modulate permeability is dependent on the presence and activation of $\mathrm{CB}_{1}$. This may be because AEA agonism of $\mathrm{CB}_{1}$ causes positive allosteric modulation of the TRPV1 receptor. Alternatively, stimulation of $\mathrm{CB}_{1}$ may cause accumulation of a second ligand, which may occupy or positively modulate TRPV1. Supporting this, it has been shown that $\mathrm{CB}_{1}$ activation increases the secretion of palmitoylethanolamide (PEA), which then may cause a conformational change in the TRPV1 receptor, greatly increasing its affinity for AEA $(34,35)$. This "entourage effect" has been seen in the endocannabinoid system, though has not yet been fully defined $(34,36)$.

Another finding within this study is that JZL184 caused increased permeability at the apical layer, but decreased permeability at the basolateral layer. Both effects were prevented by $\mathrm{CB}_{1}$ antagonism with AM251. We also confirmed that exogenous application of 2-AG (but not AEA) decreased permeability at the basolateral membrane. Not only is it interesting that 2-AG has differential effects on permeability at each membrane, but also that activation of the same basolateral $\mathrm{CB}_{1}$ receptors with AEA caused an increase in permeability, the opposite effect. The latter observation may be explained by structural differences between AEA and 2-AG at the $\mathrm{CB}_{1}$ binding site, as it has previously been observed that 2-AG can produce greater differences in intracellular $\left[\mathrm{Ca}^{2+}\right](37-$ 39). It is conceivable therefore, that differential permeability effects at the same receptor sites are due receptor bias at $\mathrm{CB}_{1}$, in addition to the effects of TRPV1 co-dependency described above. What 
is yet to be determined is the physiological mechanism that causes opposing permeability effects at different sides of the epithelium with the same ligand.

Hypoxia and inflammation in this study both caused an increase in the production of intracellular or secreted 2-AG. This supports previous suggestions that increased of endocannabinoids in human intestinal tissue acting at $\mathrm{CB}_{1}$ can lead to alterations in gastrointestinal permeability and have an anti-inflammatory in response to an inflammatory stimulus (40). For example in samples from patients with Ulcerative Colitis, Crohn's disease and Coeliac disease, all diseases of inflammation and increased permeability, levels of AEA or 2-AG have been found to be raised $(26,41,42)$. Furthermore, inflammatory bowel disease patients with the highest disease scores were found to have the highest gut AEA concentrations (43). This suggests that there may be an association between high levels of AEA and 2-AG, acting at the $\mathrm{CB}_{1}$ receptor in response to an inflammatory stimulus, leading to increased gut permeability and its secondary consequences such as translocation of bacterial and lipopolysaccharide, but also simultaneously decreasing the inflammatory response.

We found that AEA and 2-AG, or inhibition of their catabolism, exert an anti-inflammatory effect on Caco-2 epithelial cells manifesting as a reduction in IL-6 and IL-8 secretion. To support these findings we repeated parallel experiments in explant human colonic tissue and found for the first time that inhibition of FAAH and MAGL had significant anti-inflammatory effects. We found these effects were blocked by antagonism of the $\mathrm{CB}_{1}$ receptor. Coupled with our permeability findings in the Caco-2 cells, we hypothesise that the permeability-enhancing effects of AEA and 2-AG are therefore likely to be distinct from their anti-inflammatory role. In support of the anti-inflammatory effect of $\mathrm{CB}_{1}$ agonism, $\mathrm{CB}_{1}$ deficient mice are more susceptible to experimental colitis (44) and administration of AEA or FAAH to mice with TNBS-induced colitis decreases the inflammatory response $(23,27)$. Additionally, studies in explant human tissue treated with pro-inflammatory cytokines have shown that AEA appears to prevent inflammation of the epithelium measured by macro and microscopic colitis scores, and levels of matrix metalloproteinase activity $(45,46)$. The effect of 2-AG in human colonic tissue has not yet been reported. This is the first study to report the anti-inflammatory effect of endogenously enhanced AEA and 2-AG concentrations in human colonic tissue. AEA and 2-AG therefore are likely to have dual roles as anti-inflammatory and propermeability agents. As the $\mathrm{CB}_{1}$ receptor may be a target for treating diseases such as Ulcerative Colitis and Crohn's disease further work must focus on how these two agents cause their effects 
downstream from receptor activation. Additionally we investigated for a role for TRPV1, as seen in basolateral Caco-2 cells, but found that its blockade did not affect the inflammatory response.

In conclusion we have shown in a Caco-2 model of intestinal permeability that endogenous production of AEA and 2-AG increases the permeability of epithelial monolayers, both in health and disease states, despite simultaneously producing anti-inflammatory effects both in cell culture and explant human tissue. However, our data also showed that 2-AG has opposite effects on permeability at the apical and basolateral membranes, and that AEA and 2-AG activation of $\mathrm{CB}_{1}$ receptors at the basolateral membrane have opposite effects on permeability. 2-AG is upregulated by inflammation and hypoxia in this model. This complex pharmacology suggests further studies are required to fully understand the role of the endocannabinoid system in modulating gut permeability, and that pharmacological manipulation may lead to effective new therapeutic approaches to serious intestinal diseases. 


\section{References}

1. Groschwitz, K. R. and Hogan, S. P. (2009) Intestinal barrier function: molecular regulation and disease pathogenesis. J. Allergy Clin. Immunol. 124, 3-20-2

2. van der Flier, L. G. and Clevers, H. (2009) Stem cells, self-renewal, and differentiation in the intestinal epithelium. Annu. Rev. Physiol. 71, 241-260

3. Kim, Y. S. and Ho, S. B. (2010) Intestinal goblet cells and mucins in health and disease: recent insights and progress. Curr. Gastroenterol. Rep. 12, 319-330

4. Coskun, M. (2014) Intestinal Epithelium in Inflammatory Bowel Disease. Front. Med. 1, $1-5$

5. Peterson, L. W. and Artis, D. (2014) Intestinal epithelial cells: regulators of barrier function and immune homeostasis. Nat. Rev. Immunol. 14, 141-153

6. Elkouby-Naor, L. and Ben-Yosef, T. (2010) Functions of claudin tight junction proteins and their complex interactions in various physiological systems. Int. Rev. Cell Mol. Biol. 279, $1-32$

7. Shen, L. (2012) Tight junctions on the move: molecular mechanisms for epithelial barrier regulation. Ann. N. Y. Acad. Sci. 1258, 9-18

8. Fasano, A. and Nataro, J. P. (2004) Intestinal epithelial tight junctions as targets for enteric bacteria-derived toxins. Adv. Drug Deliv. Rev. 56, 795-807

9. Sonoda, N., Furuse, M., Sasaki, H., Yonemura, S., Katahira, J., Horiguchi, Y., and Tsukita, S. (1999) Clostridium perfringens enterotoxin fragment removes specific claudins from tight junction strands: Evidence for direct involvement of claudins in tight junction barrier. J. Cell Biol. 147, 195-204

10. Devane, W. A., Hanus, L., Breuer, A., Pertwee, R. G., Stevenson, L. A., Griffin, G., Gibson, D., Mandelbaum, A., Etinger, A., and Mechoulam, R. (1992) Isolation and structure of a brain constituent that binds to the cannabinoid receptor. Science 258, 1946- 
1949

11. Muccioli, G. G. (2010) Endocannabinoid biosynthesis and inactivation, from simple to complex. Drug Discov. Today 15, 474-483

12. Freund, T. F., Katona, I., and Piomelli, D. (2003) Role of endogenous cannabinoids in synaptic signaling. Physiol. Rev. 83, 1017-1066

13. Di Marzo, V. and Piscitelli, F. (2015) The Endocannabinoid System and its Modulation by Phytocannabinoids. Neurotherapeutics 12, 692-698

14. Blankman, J. L., Simon, G. M., and Cravatt, B. F. (2007) A comprehensive profile of brain enzymes that hydrolyze the endocannabinoid 2-arachidonoylglycerol. Chem. Biol. 14, $1347-1356$

15. Lee, Y., Jo, J., Chung, H. Y., Pothoulakis, C., and Im, E. (2016) Endocannabinoids in the gut. Am. J. Physiol. Gastrointest. Liver Physiol. ajpgi.00294.2015

16. Alhamoruni, a, Lee, a C., Wright, K. L., Larvin, M., and O’Sullivan, S. E. (2010) Pharmacological effects of cannabinoids on the Caco-2 cell culture model of intestinal permeability. J. Pharmacol. Exp. Ther. 335, 92-102

17. Alhamoruni, a., Wright, K. L., Larvin, M., and O\&apos;Sullivan, S. E. (2012) Cannabinoids mediate opposing effects on inflammation-induced intestinal permeability. Br. J. Pharmacol. 165, 2598-2610

18. Di Sabatino, a, Battista, N., Biancheri, P., Rapino, C., Rovedatti, L., Astarita, G., Vanoli, A., Dainese, E., Guerci, M., Piomelli, D., Pender, S. L. F., Macdonald, T. T., Maccarrone, M., and Corazza, G. R. (2011) The endogenous cannabinoid system in the gut of patients with inflammatory bowel disease. Mucosal Immunol. 4, 574-583

19. Godlewski, G., Malinowska, B., and Schlicker, E. (2004) Presynaptic cannabinoid CB1 receptors are involved in the inhibition of the neurogenic vasopressor response during septic shock in pithed rats. Br. J. Pharmacol. 142, 701-708 
20. Villanueva, A., Yilmaz, S. M., Millington, W. R., Cutrera, R. A., Stouffer, D. G., Parsons, L. H., Cheer, J. F., and Feleder, C. (2009) Central cannabinoid 1 receptor antagonist administration prevents endotoxic hypotension affecting norepinephrine release in the preoptic anterior hypothalamic area. Shock 32, 614-620

21. Caraceni, P., Pertosa, A. M., Giannone, F., Domenicali, M., Grattagliano, I., Principe, A., Mastroleo, C., Perrelli, M. G., Cutrin, J., Trevisani, F., Croci, T., and Bernardi, M. (2009) Antagonism of the cannabinoid CB-1 receptor protects rat liver against ischaemiareperfusion injury complicated by endotoxaemia. Gut 58, 1135-1143

22. Matsuda, K., Mikami, Y., Takeda, K., Fukuyama, S., Egawa, S., Sunamura, M., Maruyama, I., and Matsuno, S. (2005) The cannabinoid 1 receptor antagonist, AM251, prolongs the survival of rats with severe acute pancreatitis. Tohoku J. Exp. Med. 207, 99-107

23. Engel, M. a., Kellermann, C. a., Rau, T., Burnat, G., Hahn, E. G., and Konturek, P. C. (2008) Ulcerative colitis in AKR mice is attenuated by intraperitoneally administered anandamide. J. Physiol. Pharmacol. 59, 673-689

24. Troy-Fioramonti, S., Demizieux, L., Gresti, J., Muller, T., Vergès, B., and Degrace, P. (2015) Acute activation of cannabinoid receptors by anandamide reduces gastrointestinal motility and improves postprandial glycemia in mice. Diabetes $\mathbf{6 4}, 808-818$

25. Harvey, B. S., Nicotra, L. L., Vu, M., and Smid, S. D. (2013) Cannabinoid CB2 receptor activation attenuates cytokine-evoked mucosal damage in a human colonic explant model without changing epithelial permeability. Cytokine 63, 209-217

26. D’Argenio, G., Valenti, M., Scaglione, G., Cosenza, V., Sorrentini, I., and Di Marzo, V. (2006) Up-regulation of anandamide levels as an endogenous mechanism and a pharmacological strategy to limit colon inflammation. FASEB J. 20, 568-570

27. Shamran, H., Singh, N. P., Zumbrun, E. E., Murphy, A., Taub, D. D., Mishra, M. K., Price, R. L., Chatterjee, S., Nagarkatti, M., Nagarkatti, P. S., and Singh, U. P. (2016) Fatty acid amide hydrolase (FAAH) blockade ameliorates experimental colitis by altering microRNA expression and suppressing inflammation. Brain. Behav. Immun. 
28. Sałaga, M., Mokrowiecka, A., Zakrzewski, P. K., Cygankiewicz, A., Leishman, E., Sobczak, M., Zatorski, H., Małecka-Panas, E., Kordek, R., Storr, M., Krajewska, W. M., Bradshaw, H. B., and Fichna, J. (2014) Experimental colitis in mice is attenuated by changes in the levels of endocannabinoid metabolites induced by selective inhibition of fatty acid amide hydrolase (FAAH). J. Crohns. Colitis 8, 998-1009

29. Koay, L. C., Rigby, R. J., and Wright, K. L. (2014) Cannabinoid-induced autophagy regulates suppressor of cytokine signaling-3 in intestinal epithelium. Am. J. Physiol. Gastrointest. Liver Physiol. 307, G140-8

30. Shore, D. M., Baillie, G. L., Hurst, D. H., Navas, F., Seltzman, H. H., Marcu, J. P., Abood, M. E., Ross, R. A., and Reggio, P. H. (2014) Allosteric Modulation of a Cannabinoid G Protein-coupled Receptor. J. Biol. Chem. 289, 5828-5845

31. Richardson, D., Ortori, C. A., Chapman, V., Kendall, D. A., and Barrett, D. A. (2007) Quantitative profiling of endocannabinoids and related compounds in rat brain using liquid chromatography-tandem electrospray ionization mass spectrometry. Anal. Biochem. 360, $216-226$

32. Kathuria, S., Gaetani, S., Fegley, D., Valiño, F., Duranti, A., Tontini, A., Mor, M., Tarzia, G., Rana, G. La, Calignano, A., Giustino, A., Tattoli, M., Palmery, M., Cuomo, V., and Piomelli, D. (2002) Modulation of anxiety through blockade of anandamide hydrolysis. Nat. Med. 9, 76-81

33. Piomelli, D., Tarzia, G., Duranti, A., Tontini, A., Mor, M., Compton, T. R., Dasse, O., Monaghan, E. P., Parrott, J. A., and Putman, D. (2006) Pharmacological profile of the selective FAAH inhibitor KDS-4103 (URB597). CNS Drug Rev. 12, 21-38

34. Smart, D., Jonsson, K.-O., Vandevoorde, S., Lambert, D. M., and Fowler, C. J. (2002) "Entourage" effects of $\mathrm{N}$-acyl ethanolamines at human vanilloid receptors. Comparison of effects upon anandamide-induced vanilloid receptor activation and upon anandamide metabolism. Br. J. Pharmacol. 136, 452-458

35. Jonsson, K. O., Vandevoorde, S., Lambert, D. M., Tiger, G., and Fowler, C. J. (2001) 
Effects of homologues and analogues of palmitoylethanolamide upon the inactivation of the endocannabinoid anandamide. Br. J. Pharmacol. 133, 1263-1275

36. Ho, W.-S. V, Barrett, D. A., and Randall, M. D. (2008) "Entourage" effects of Npalmitoylethanolamide and N-oleoylethanolamide on vasorelaxation to anandamide occur through TRPV1 receptors. Br. J. Pharmacol. 155, 837-846

37. Sugiura, T., Kodaka, T., Kondo, S., Tonegawa, T., Nakane, S., Kishimoto, S., Yamashita, A., and Waku, K. (1996) 2-Arachidonoylglycerol, a putative endogenous cannabinoid receptor ligand, induces rapid, transient elevation of intracellular free $\mathrm{Ca} 2+$ in neuroblastoma x glioma hybrid NG108-15 cells. Biochem. Biophys. Res. Commun. 229, $58-64$

38. Sugiura, T., Kodaka, T., Kondo, S., Nakane, S., Kondo, H., Waku, K., Ishima, Y., Watanabe, K., and Yamamoto, I. (1997) Is the cannabinoid CB1 receptor a 2arachidonoylglycerol receptor? Structural requirements for triggering a $\mathrm{Ca} 2+$ transient in NG108-15 cells. J. Biochem. 122, 890-895

39. Sugiura, T., Kodaka, T., Nakane, S., Miyashita, T., Kondo, S., Suhara, Y., Takayama, H., Waku, K., Seki, C., Baba, N., and Ishima, Y. (1999) Evidence that the cannabinoid CB1 receptor is a 2-arachidonoylglycerol receptor. Structure-activity relationship of 2arachidonoylglycerol, ether-linked analogues, and related compounds. J. Biol. Chem. 274, 2794-2801

40. Di Marzo, V. and Izzo, a a. (2006) Endocannabinoid overactivity and intestinal inflammation. Gut 55, 1373-1376

41. D’Argenio, G., Petrosino, S., Gianfrani, C., Valenti, M., Scaglione, G., Grandone, I., Nigam, S., Sorrentini, I., Mazzarella, G., and Di Marzo, V. (2007) Overactivity of the intestinal endocannabinoid system in celiac disease and in methotrexate-treated rats. J. Mol. Med. 85, 523-530

42. Guagnini, F., Valenti, M., Mukenge, S., Matias, I., Bianchetti, a, Di Palo, S., Ferla, G., Di Marzo, V., and Croci, T. (2006) Neural contractions in colonic strips from patients with 
diverticular disease: role of endocannabinoids and substance P. Gut 55, 946-953

43. Pastor Rojo, O., López San Román, A., Albéniz Arbizu, E., de la Hera Martínez, A., Ripoll Sevillano, E., and Albillos Martínez, A. (2007) Serum lipopolysaccharide-binding protein in endotoxemic patients with inflammatory bowel disease. Inflamm. Bowel Dis. 13, 269277

44. Massa, F., Marsicano, G., Hermann, H., Cannich, A., Monory, K., Cravatt, B. F., Ferri, G.L., Sibaev, A., Storr, M., and Lutz, B. (2004) The endogenous cannabinoid system protects against colonic inflammation. J. Clin. Invest. 113, 1202-1209

45. Harvey, B. S., Sia, T. C., Wattchow, D. a., and Smid, S. D. (2014) Interleukin 17A evoked mucosal damage is attenuated by cannabidiol and anandamide in a human colonic explant model. Cytokine 65, 236-244

46. Nicotra, L. L., Vu, M., Harvey, B. S., and Smid, S. D. (2013) Prostaglandin ethanolamides attenuate damage in a human explant colitis model. Prostaglandins Other Lipid Mediat.

100-101, 22-29

\section{Author Contributions}

Conception and design of the study; Karen L. Wright, Saoirse E. O'Sullivan

Generation, collection, assembly, analysis and/or interpretation of data; Daniel G Couch, Mustafa A. Karwad, Elena Theophilidou, Sarir Sarmad, Karen L. Wright, Saoirse E. O’Sullivan

Drafting or revision of the manuscript; all

Approval of the final version of the manuscript: all 


\section{Acknowledgments:}

No Disclosures

\section{Figure Legends}

Figure 1. Increasing anandamide concentrations (using URB597) increases Caco-2 permeability via $\mathrm{CB} 1$.

The effects of URB597 applied apically (A) or basolaterally (C). Integrated response over time (area under curve) on the effects of URB597 in the presence of various receptor antagonists (B and D), on Caco-2 permeability as measured by TEER. Data are given as means and standard error bars S.E.M $(n=3)$. Concentration response curves were compared by two-way repeated measures ANOVA with Dunnett's post-hoc test comparing against the vehicle response $\left(^{*}\right)$. Integrated response over time (AUC) data were compared using one-way ANOVA with post hoc analysis of selected pairs (* verses vehicle, $\dagger$ verses URB597 $3 \mu \mathrm{M}$ alone; ${ }^{*} \mathrm{p}<0.05,{ }^{*} * \mathrm{p}<0.01$, $* * * \mathrm{p}<0.001, * * * * \mathrm{p}<0.0001, \dagger \dagger \dagger \dagger<0.0001)$.

Figure 2. Increasing 2-AG concentrations (using JZL184) modulates Caco-2 permeability via CB.

The effects of JZL184 applied apically (A) and basolaterally (C) on Caco-2 permeability as measured by TEER. Integrated response over time (area under curve) on the effects of receptors antagonists on JZL184 apically (B) and basolaterally (D). The effects of basolateral application of AEA and 2-AG on Caco-2 permeability (E). Data are given as means and standard error bars S.E.M. $(n=3)$. Concentration-response curves were compared by two-way repeated measures ANOVA with Dunnett's post-hoc test comparing against the vehicle response (*). Integrated response over time (AUC) data were compared using one-way ANOVA with post hoc analysis of selected pairs (* denotes verses vehicle; $* \mathrm{p}<0.05, * * \mathrm{p}<0.01, * * * \mathrm{p}<0.001, * * * * \mathrm{p}<0.0001)$.

Figure 3. Increasing AEA or 2-AG causes further increases in permeability after inflammation or hypoxia.

A. The effect of URB597 and JZL184 applied after 24 hours inflammatory cytokine treatment on Caco-2 permeability as measured by TEER. B. The effect of URB597 and JZL184 after 4 hours of hypoxia on Caco-2 permeability as measured by TEER (B). Data are given as means with error bars 
representing SEM $\left(\mathrm{n}=3\right.$, ${ }^{*} \mathrm{P}<0.05$, ** $\left.\mathrm{P}<0.01 * * * \mathrm{P}<0.001\right)$, comparing between control and experimental data by two-way ANOVA with Dunnett's post-hoc test.

Figure 4. $C B_{1}$ contributes to increased permeability associated with inflammation but not hypoxia.

The effect of URB597 and JZL184 (apical and basolateral) in Caco-2 CB 1 kd cells on permeability as measured by TEER (A). The effect of pro-inflammatory cytokines (B) and hypoxia (C) in wild type and $\mathrm{CB}_{1} \mathrm{KO}$ Caco-2 cells on permeability as measured by TEER. Data are given as means with error bars representing SEM $(* \mathrm{p}<0.05$, ** $\mathrm{p}<0.01 * * * \mathrm{p}<0.001$ compared to control, \# $\mathrm{p}<0.05$, \#\# $\mathrm{p}<0.01$ \#\# compared to wild type Caco-2 cells). Data were compared by ANOVA with Dunnett's post-hoc test.

Figure 5. 2-AG is increased by hypoxia and inflammation, and both AEA and 2-AG are anti-inflammatory in Caco-2 cells.

The effects of hypoxia and inflammation on the endogenous production of AEA (A) and 2-AG (B) in cultured Caco-2 cells determined by LC-MS. The effects of AEA and 2-AG on cytokine production in Caco- 2 cells determined by ELISA ( $\mathrm{C}$ and $\mathrm{D}$ respectively). Data are given as means and standard error bars S.E.M, $(\mathrm{n}=6, * \mathrm{P}<0.05, * * \mathrm{P}<0.01 * * * \mathrm{P}<0.001)$, comparing control and experimental data by one-way ANOVA with Dunnett's post-hoc test.

Figure 6: URB597 and JZL184 are anti-inflammatory in the human colon, acting via CB1

The effects of URB597 and JZL184 on the secretion of GM-CSF (A), IL-12 (B), IL-13 (C) IL-15 (D), MIP-1a (E) \& IL-1b (F) in response to an inflammatory protocol in explant human colonic tissue in the presence of antagonists of CB1 (AM251) and TRPV1 (SB366791), measured by multiplex (compared using repeated measures ANOVA, $n=7$ ). Data presented as mean $+/$ - SEM per condition. $*$ represent significant difference from vehicle, $*<0.05, * *<0.01, * * *<0.001$. 